\title{
Thoracic Tuberculous Spondylitis: Posterior Approach Single-Stage Stabilization, Debridement, and Local Grafting
}

\section{Hamdy Tammam, Elsayed Said}

Department of Orthopaedic Surgery, Faculty of Medicine, South Valley University, Qena, Egypt.

\section{Abstract: \\ Background: Different approaches are employed to treat patients with Pott's disease who are candidates for surgical intervention. Each of these approaches has advantages and disadvantages.}

Objectives: This retrospective study presents the surgical, clinical, and radiological outcomes of posterior alone single-stage debridement and grafting of single-level tuberculous discitis using local graft from the decompression and nearby spinous processes.

Patients and Methods: Between 2012 to June 2016, 15 patients with thoracic tuberculous spondylitis were operated up through posterior approach starting with one side fixation thorough debridement of the lesion and the use of local graft form decompression and spinous process bone. Clinical evaluation was done using Visual Analogue Scale (VAS) for back pain, Oswestry Disability Index (ODI), and Frankel Grade classification. Radiological assessment of kyphotic angle and fusion was also performed.

Results: The mean operative time was $115.3 \pm 23.6$ minutes. The mean amount of blood loss was $571.3 \pm 142.4 \mathrm{ml}$. Hospital stay ranged from 3 to 7 days (mean $4 \pm 0.6$ days). Patients were followed for $30.27 \pm 6.5$ months. All patients showed significant improvement in clinical and radiological parameters. Twelve patients showed neurological improvement. One patient required reoperation for neurological deterioration. Radiological follow-up showed solid fusion within 6 months postoperatively.

Conclusion: Single-stage debridement of thoracic Pott's lesion with the use of transpedicular fixation and local graft under perioperative coverage of antitubercular chemotherapy yielded satisfactory results avoiding the need for the more morbid and technically demanding anterior procedures and the graft donor site morbidity.

Keywords: Pott's disease, Tuberculous Spondylitis, Posterior surgery, Local graft.

\section{Introduction}

The prevalence of TB has peaked during the past decades secondary to the pandemic of acquired immunodeficiency syndrome (AIDS), the global migration phenomenon, and the prevailing poor living and sanitary environment (Rajasekaran et al., 2018). It is the most encountered reason for infective spondylodiscitis affecting almost 2 million individuals worldwide (Boachie-Adjei et al., 2013).

Tuberculous Spondylitis, also known as Pott's disease was first described by Sir Percival Pott in 1779 in patients with paraplegia and kyphotic deformities (Dobson, 1972). Generally, Pott's disease has a bimodal age distribution, with one peak at 20 - 30 years and a second peak at $60-70$ years (Pigrau-Serrallach and Rodríguez-Pardo, 2013). 
Pott's Paraplegia is the most common and serious complication. It affects up to $50 \%$ of patients with spinal TB. This could be explained by the insidious onset, late diagnosis, and high predilection for thoracic region with narrow spinal canal (Pigrau-Serrallach and RodríguezPardo, 2013). Late onset paraplegia may occur months or years after healing secondary to cord stretching by the associated deformity (K., 2010). Thus, early diagnosis and treatment is essential to avoid spinal deformity and prevent permanent neurological deficit.

The aim of treatment in Pott's disease is debridement of the affected segment, decompression of the spinal canal, correction of the deformity and solid bony union to avoid late onset paraplegia from the increasing kyphosis (Jain and Jain, 2012). Although antitubercular drugs may inactivate the infection, vertebral collapse and deformity may continue until the consolidation of the healthy vertebral bodies anteriorly. Therefore, timely surgical intervention can prevent the development of severe deformity especially in high-risk patients such as children, loss of one vertebral body, junctional lesions, kyphosis more than 30 and 'spine at risk' radiological signs (retropulsion, toppling, lateral translation, and separation of the facet joints) (Rajasekaran, 2001, Rajasekaran, 2007). The affected segment can be addressed via posterior, anterior or combined approaches. However, the ideal surgical approach is not yet clears(Benli et al., 2004, Bian et al., 2020).

This retrospective study evaluates the surgical, clinical, and radiological outcomes of single-stage posterior-only stabilization, debridement and grafting of single-level thoracic tuberculous discitis using a local bone graft.

\section{Patients and methods}

We retrospectively reviewed 15 patients suffering single-level thoracic tuberculous discitis with neurological deficit who underwent posterior debridement and instrumented fusion using local graft harvested from decompression plus or minus tips of the nearest two or three spinous processes after preparation of the fusion bed by curettage of the endplates between 2012 and 2016 (Figures 1 and 2).

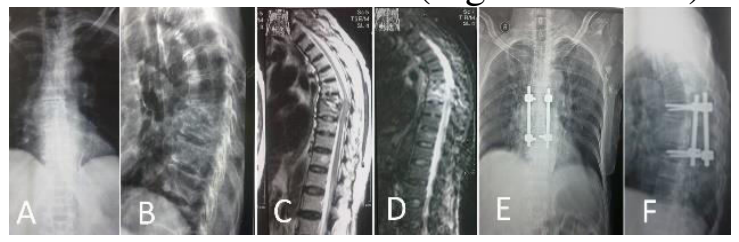

Figure 1A 75-year-old female with D7/8 lesion. (A-D) Preoperative imaging showing vertebral body destruction, kyphosis, and spinal cord compression. (E-F) Postoperative imaging after stabilization, debridement, and local bone grafting via posterior-only approach.

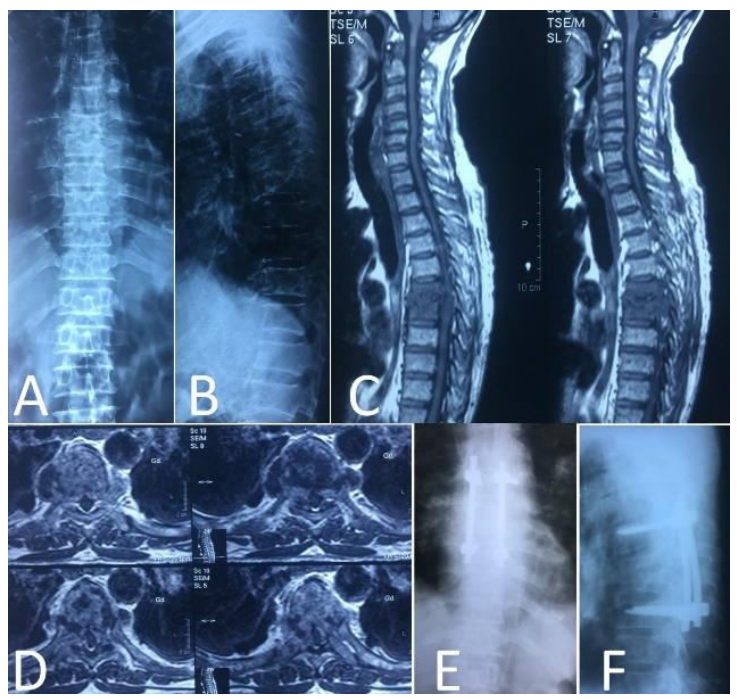

Figure 2.A 50-year-old male with D6/7 lesion. (A-D) Preoperative imaging showing severe vertebral body destruction with abscess formation and spinal cord compression. (E-F) Postoperative imaging after stabilization, debridement, and local bone grafting via posterior-only approach.

Indications of surgery in included patients were:

- Back pain that was resistant to antitubercular drugs for two months or progressive neurological deterioration.

- Kyphotic deformity $\geq 30^{\circ}$ or spinal instability. 
- $\quad$ Spinal cord decompression $(\geq 25 \%$ of the spinal canal diameter compromised).

- Vertebral body destruction ( $\geq 30 \%$ of vertebral height).

- Paraspinal abscess.

We excluded patients with the following criteria:

- Lesion not involving thoracic spine.

- Neurologically free.

- Multilevel or skip lesions.

Ethical approval for this study was waived due to the retrospective nature of the study. Informed consent was obtained from all patients included in the study.

All patients were evaluated clinically using Visual Analogue Scale (VAS) for back pain and Oswestry Disability Index (ODI). Preoperative neurological status was documented using Frankel Grade classification (Table 1) (Frankel et al., 1969). Radiologically, the patients were assessed by x-ray and MRI to confirm the diagnosis, detect the affected level, measure the kyphotic angle using Cobb angle method (Kuklo et al., 2001, Keynan et al., 2006), estimate the degree of compression and to exclude skipped levels. All patients underwent surgery under coverage of antitubercular drugs.

Table 1.Frankel Grade classification for neurological deficit

\begin{tabular}{lll}
\hline Grade & $\begin{array}{l}\text { Complete } \\
\text { injury }\end{array}$ & $\begin{array}{l}\text { No motor or } \\
\text { sensory function } \\
\text { detected below } \\
\text { level of lesion } \\
\text { Grade }\end{array}$ \\
B & $\begin{array}{l}\text { Sensory } \\
\text { only }\end{array}$ & $\begin{array}{l}\text { No motor function } \\
\text { detected below } \\
\text { level of lesion, } \\
\text { some sensory } \\
\text { function below } \\
\text { level of lesion } \\
\text { preserved. }\end{array}$ \\
& & $\begin{array}{l}\text { Some voluntary } \\
\text { motor function } \\
\text { preserved below } \\
\text { level of lesion but } \\
\text { too weak to serve }\end{array}$
\end{tabular}

\begin{tabular}{lll} 
& & $\begin{array}{l}\text { any useful } \\
\text { purpose, sensation } \\
\text { may or may not } \\
\text { be preserved }\end{array}$ \\
Grade & $\begin{array}{l}\text { Motor } \\
\text { D }\end{array}$ & $\begin{array}{l}\text { Functionally } \\
\text { useful voluntary } \\
\text { motor function } \\
\text { below level of } \\
\text { injury is preserved } \\
\text { Normal motor and } \\
\text { sensory function } \\
\text { E }\end{array}$ \\
& & Recovery level of \\
& & $\begin{array}{l}\text { lesion, abnormal } \\
\text { reflexes may } \\
\text { persist }\end{array}$ \\
\hline
\end{tabular}

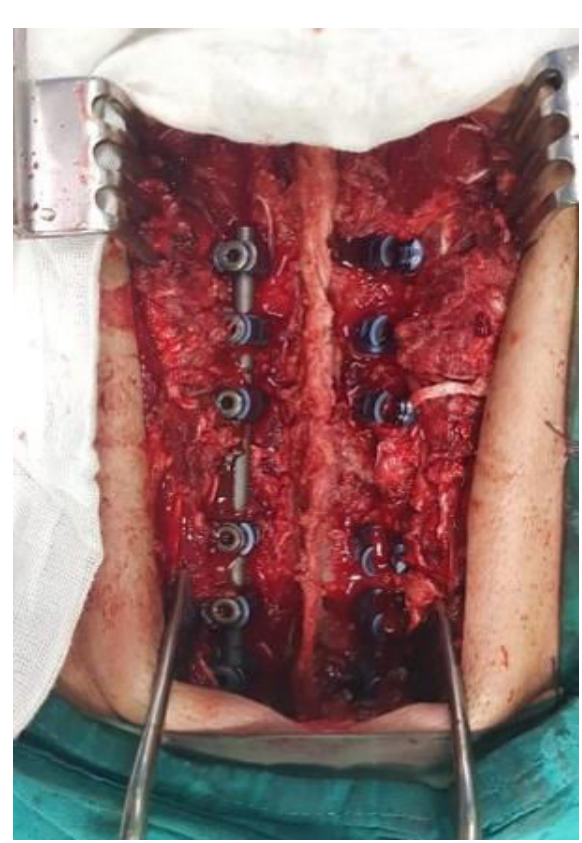

Figure 3 Intraoperative stabilization of the spine by a single rod prior to debridement.

\section{Surgical technique}

Under general anesthesia, each patient was positioned in the prone position with protection against pressure necrosis. The affected level was determined either by the kyphosis level or imaging. Midline posterior skin incision centered over the affected segment was done followed by subperiosteal dissection using cobb elevator and diathermy to expose the laminae, facets, transverse processes, and costovertebral junctions two levels above and below the affected level. Pedicle 
screws were inserted in the targeted vertebrae and one rod was applied to stabilize the spine (Figure 3).

Costotransversectomy of the affected level was carried out with meticulous debridement of the caseous material using bone curettes of different sizes and shapes together with biopsy. The tips of the adjacent spinous processes were harvested to augment the bone from decompression which will be used as a local graft. The well-prepared graft was applied to the well-prepared intervertebral space. The other rod was installed with contouring of the rod to help correction deformity. Finally, the wound was closed in layers over a suction drain. Mobilization was allowed postoperatively whenever possible. Patients were advised to use a rigid thoracolumbar brace for 6 weeks. The suction removed 24- 48 hours postoperatively. Patients were discharged 3-7 days postoperatively for outpatient clinic follow-up after 2 weeks, 1.5, 3,6,12 months and every year after.

\section{Outcome measurement}

Intraoperatively, operation time and amount of bleeding were recorded. Patients were evaluated for VAS, ODI, and neurological status postoperatively and at regular follow-ups. X-rays were done postoperatively and after 1.5, 3, 6 and 12 months and then yearly for assessment of kyphosis using Cobb angle method (Figure 4) (Kuklo, Polly et al., 2001, Keynan, Fisher et al., 2006), fusion using criteria described by Lee et al (Lee et al., 1995), and construct integrity.

\section{Statistical analysis}

Description of means and standard deviation for quantitative variables and frequencies and percentage for qualitative variables were calculated using SPSS Version 22.0 (IBM Corp, Armonk, NY). Preoperative and postoperative results were compared using paired sample-t-test. The level of significance was set at $\mathrm{p}<$ 0.05 .

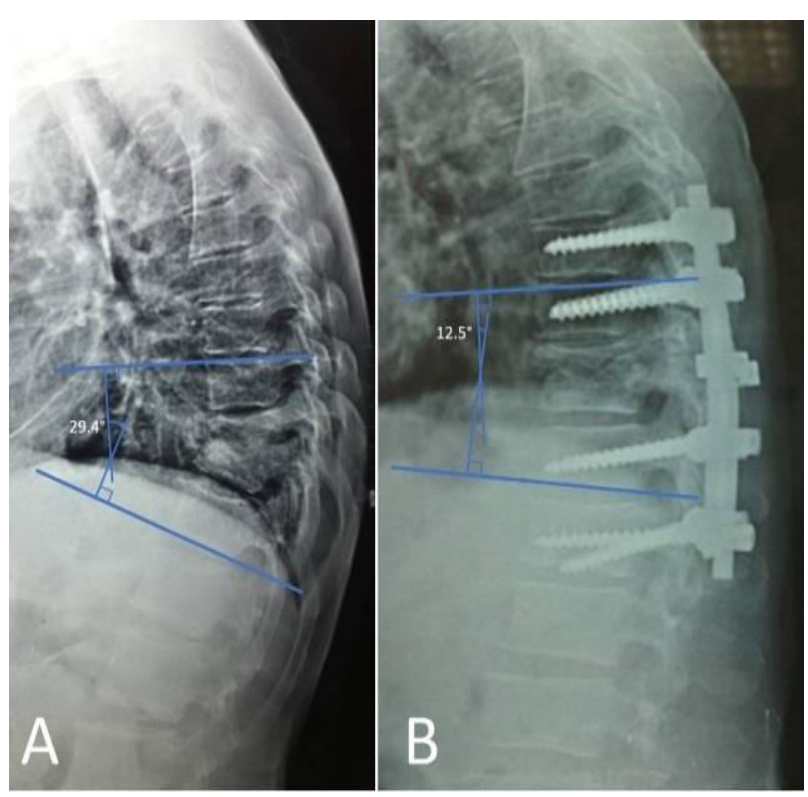

Figure 4 Measurement of kyphotic angle using Cobb angle method. (A) preoperatively and (B) postoperatively.

\section{Results}

Demographic data as regards age, gender, affected level, and preoperative neurological status are summarized in Table 2.

The mean follow-up duration was $30.27 \pm$ 6.5 months and ranged from 15 to 38 months. The mean operative time was $115.3 \pm 23.6$ minutes. The mean amount of blood loss was $571.3 \pm 142.4 \mathrm{ml}$. Hospital stay ranged from 3 to 7 days (mean $4 \pm 0.6$ days). 
Table 2: Patients' demographic data (N = 15)

\begin{tabular}{lc}
\hline Parameter & Value \\
\hline $\begin{array}{l}\text { Age*, years } \\
\text { Gender** }\end{array}$ & $52.33 \pm 7.8(45-70)$ \\
Male & $3(20)$ \\
Female & $12(80)$ \\
Level $^{* * *}$ & \\
D6/7 & $3(20)$ \\
D7/8 & $3(20)$ \\
D10/11 & $4(26.7)$ \\
D11/12 & $5(33.3)$ \\
Neurological & \\
deficit & \\
Frankel B & $3(20)$ \\
Frankel C & $12(80)$ \\
Follow up & \\
months & $30.27 \pm 6.5$ \\
" Data are presented as mean \pm SD (range) \\
** Data are presented as No. (\%)
\end{tabular}

VAS for back pain improved significantly from $7.3 \pm 0.8$ preoperatively to $2.8 \pm 0.9$ at last follow-up $(\mathrm{P}=0.000)$. ODI also improved significantly from $30.8 \pm 9.1$ preoperatively to $6.3 \pm 1.4$ at last followup $(\mathrm{P}=0.000)$. Neurological deficits improved within 3 months after surgery in 12 patients. Ten patients improved to grade $\mathrm{A}$, and two patients improved to grade B. One patient showed progressive spasticity and found to develop new higher level of spondylitis with cord compression which required reoperation.

The mean kyphotic angle improved from $30.4^{\circ} \pm 5.2^{\circ}$ (range from $39.5^{\circ}$ to $25.5^{\circ}$ ) preoperatively to $8.23^{\circ} \pm 2.1^{\circ}$ postoperatively (Figure 4). At the final follow-up, the mean kyphotic angle was $9.75^{\circ} \pm 1.9^{\circ}$ and the mean loss of correction was only $1.52^{\circ}$.

Radiological fusion achieved in all patients within $6.2 \pm 1.4$ months with solid big bilateral trabeculae (Figure 5).

Two cases were complicated by superficial infection and managed by systemic antibiotics and frequent dressings. The construct integrity maintained till last follow for in all cases except a screw breakage occurred in one case without clinical impact.

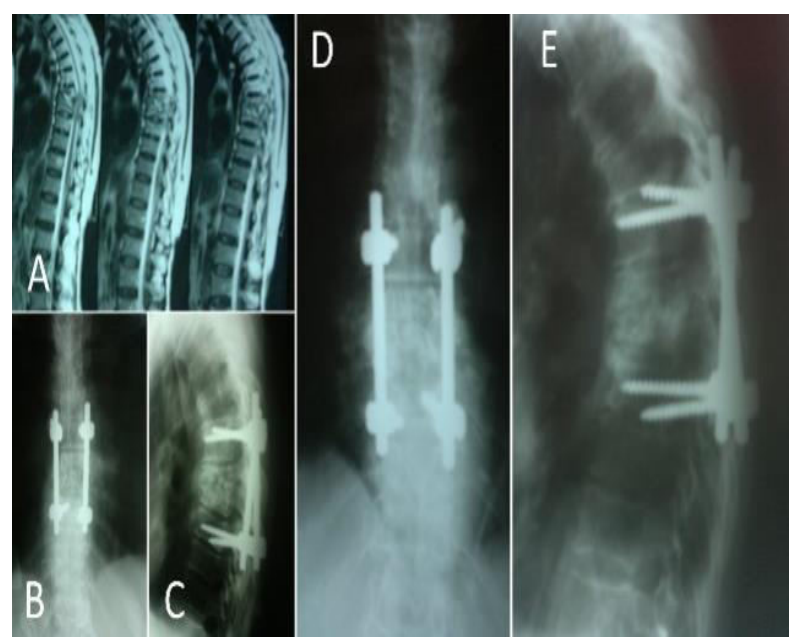

Figure 5 A 46-year-old female with D7/8 lesion. (A) Preoperative MRI. (B-C) 2month follow-up $x$-ray following transpedicular screw fixation, debridement and grafting via posterior-only approach. (D-E) 6-month follow-up $x$-ray showing evidence of fusion.

\section{Discussion}

Extrapulmonary TB (EPTB) has a low estimated incidence of only 3\% (Luk, 1999). Almost $10 \%$ of EPTB affect the musculoskeletal system. The vertebral column accounts for $50 \%$ of cases of skeletal TB (STB). The thoracolumbar spine is by the far the most frequently affected segment, followed by the lumbar spine and the cervical spine (Kulchavenya, 2014). The clinical presentation of spinal TB is multifactorial, including the virulence of the organism, the host immunity, severity and duration of the disease, site of the disease, and the presence of complications such as cold abscess, sinuses, kyphotic deformity, spinal instability, and neurological deficit (Wibaux et al., 2013).

Antitubercular chemotherapy is the gold standard of treatment in both complicated and uncomplicated TB (Rajasekaran and Khandelwal, 2013). However, surgical intervention is necessary in cases with vertebral body destruction, severe kyphotic deformity, large abscess formation, and 
spinal cord compression causing neurological deficit. The primary objectives of surgical treatment are eradication of the infection, decompression of the neural element, promoting early neurological recovery, prevention, or correction of the deformity, and restore and maintain the spine stability (Fisahn et al., 2017). Oga et al demonstrated safety of instrumentation even in active stages of the disease as tubercle bacilli, unlike pyogenic organisms, are incapable of forming biofilms (Oga et al., 1993). Nevertheless, the optimal surgical modality for tuberculosis remains controversial.

Pott's disease primarily affects the anterior spinal column. Therefore, anterior approach described by AR Hodgson, provides adequate exposure, better visualization, direct access to the relevant pathology, radical debridement, wide decompression, and reconstruction of the anterior column (Hodgson et al., 1960, Varatharajah et al., 2014). From a theoretical point of view, these advantages would improve fusion rates and achieve favorable outcomes. However, anterior procedures have a several disadvantages. osteoporosis associated with the infection hinders adequate fixation in the thoracic and lumbar region (Garg et al., 2012). Moreover, anterior approaches do not enable optimal kyphosis correction with significant loss of correction postoperatively (Wang et al., 2014).

Combined anterior and posterior approaches seem to be preferrable in patients with marked osteoporosis, multiple-level involvement, and severe kyphotic deformities (Chen et al., 2002). While anterior approach eliminates infected foci and provides adequate neural decompression and rigid anterior reconstruction, posterior fixation ensures better deformity correction and eliminates the stress on anterior grafts to prevent loss of sagittal deformity correction (Turgut, 2001). However, combined procedures are technically challenging with high morbidity rates (Bian, Gui et al., 2020).

On the other hand, posterior spinal surgery is becoming increasingly popular thanks to the development of pedicle screw technology. Transpedicular posterior instrumentation allows circumferential neuronal decompression, better deformity control through pedicle screws, and possibility of extension of instrumentation whenever required in addition to lowering morbidity and mortality rates (Broner et al., 1996, Chen et al., 2003, Lee et al., 2006, Bian, Gui et al., 2020). Furthermore, Broner et al stated that the immobilization achieved using posterior instrumentation might be useful for suppressing infection and providing a stable environment to prevent $\mathrm{TB}$ recurrence (Broner, Garland et al., 1996).

In our study, 15 patients with single level thoracic tuberculous discitis with neurological deficit underwent posterior debridement and instrumented fusion using local bone graft obtained from decompression plus or minus tips of the nearest two or three spinous processes. We retrospectively reviewed the surgical, clinical, and radiological parameters. Overall, we found significant improvements in patients' outcomes in terms of VAS, ODI, ASIA, and Cobb angle.

Surgical outcomes of posterior transpedicular approach were evaluated by previous studies. Xiyang Wang et al found that posterior approach group had a shorter operating time, less intraoperative bleeding and a shorter time hospital stay compared to anterior approach (Wang, Pang et al., 2014). In a retrospective study Suryakant Singh et al, the mean operation time was $260 \pm 30$ minutes, ranging from 180 to 540 minutes, the mean hospital stay for postoperative rehabilitation was 15 days (Singh et al., 2017). Similarly, our cohort had an operation time of $115.3 \pm 23.6$ minutes. The average blood loss intraoperatively was $571.3 \pm 142.4 \mathrm{ml}$. All 
patients required a hospital stay ranging between 3 to 7 days.

Back pain is the most predominant and disabling symptom in spinal TB. In our series, all patients showed statistically significant improvement in clinical outcomes compared to preoperative status. VAS scores for back pain improved significantly from $7.3 \pm 0.8$ preoperatively to $2.8 \pm 0.9$ at last follow-up. ODI improved significantly from $30.8 \pm 9.1$ preoperatively to $6.3 \pm 1.4$ at last followup. Our findings were consistent with previous studies. Sahoo et al achieved complete pain relief, with the final VAS score ranging from 0 to 2 (Sahoo et al., 2012). ODI was assessed by Suryakant Singh et al, where the mean ODI score improved from 32.52 preoperatively to 13.42 postoperatively and dropped to almost zero at 6-month follow-up (Singh, Dawar et al., 2017). In another study by Zeng et al to evaluate one stage posterior only approach, VAS of pain was $7.8 \pm 2.1$ preoperatively, declined to $4.2 \pm 1.8$ postoperatively and $1.4 \pm 0.6$ during the final follow-up (Zeng et al., 2015).

Neurological complications associated with spinal $\mathrm{TB}$ are usually attributed to instability or mechanical compression by cold abscess, or sequestrum. Late-onset neurological deficit are explained by ossification of ligamentum flavum proximal to the kyphosis (Hodgson et al., 1967). In our study, complete neurological recovery was observed in ten patients. One patient showed neurological deterioration and required revision surgery. Significant neurological improvement following posterior spinal surgery in TB patients has been documented by previous authors as well. Zeng et al reported one case improved by three grades, 21 cases improved by two grades, and 12 cases improved by one grade (Zeng, Zhang et al., 2015). Yin et al found that the 25 patients with preoperative neurologic deficit recovered to normal, except for 2 patients who incompletely recovered (Yin et al., 2018).
Spinal TB tends to affect the anterior column. Progressive destruction of anterior structures results in kyphotic deformity of spine. Correction of deformity and maintenance of correction are key elements of a successful surgery. Singh et al accomplished a mean correction of $10.28^{\circ}$. At the final follow-up, the mean kyphotic angle was $9.98^{\circ}$ and the mean loss of correction was $2.40^{\circ}$ (Singh, Dawar et al., 2017). Another study showed improvement of Kyphosis angle from $34.1 \pm 12.3^{\circ}$, preoperatively to $8.2 \pm$ $1.8^{\circ}$, postoperatively $(\mathrm{P}<0.05)$. Kyphosis angle was $9.7 \pm 2.0^{\circ}$ at final follow-up with a loss of correction of only $1.5 \pm 0.6^{\circ}$ (Zeng, Zhang et al., 2015). Similarly, our cohort demonstrated improvement of kyphosis from $30.4^{\circ} \pm 5.2^{\circ}$ preoperatively to $8.23^{\circ} \pm 2.1^{\circ}$ postoperatively with statistically insignificant loss of correction at final follow-up. However, a systematic review and meta-analysis concluded that anterior, posterior, and combined approaches had similar results as regards kyphotic angle correction (Bian, Gui et al., 2020).

We also evaluated fusion rate as a parameter for favorable radiological outcome. Radiological fusion was achieved in all cases within nearly 6 months. Similarly, in a previous study 55 of 60 patients had a successful bony fusion within a mean of $6 \pm 1.5$ months (Singh, Dawar et al., 2017). Others studied 25 patients with thoracic TB who received posterior surgery and achieved bone fusion within $6.7 \pm 1.9$ months postoperatively (Yin, Yan et al., 2018). In our study, local bone graft necessary for fusion, was harvested from decompression plus or minus tips of the nearest two or three spinous processes. It provides bone graft of adequate quality and quantity while preventing donor site related complications associated with iliac crest bone graft (ICBG).

Our study has several limitations. It is a retrospective cohort with a small sample size. This limitation can be explained by 
the relatively uncommon presentation of single level thoracic TB and the progress in antituberculosis chemotherapy which has decreased the need for surgical intervention. Another limitation is the lack of comparison of the posterior approach to other surgical options such as anterior and combined procedures. Therefore, future prospective trials with larger sample size comparing different surgical modalities are required to reach a more solid conclusion regarding the best surgical approach to address complicated spinal TB.

\section{Conclusion}

Single stage debridement of thoracic Pott's lesion with use of transpedicular fixation and local graft achieved favorable clinical and radiological outcomes while avoiding the need for the more morbid and technically demanding anterior procedure and the graft doner site morbidity.

Ethical approval

Ethical approval for this study was waived due to the retrospective nature of the study.

\section{Conflict of interest}

The authors of the study have no conflict of interest related to this publication.

\section{References}

Benli IT, Alanay A, Akalin S, Kiş M, Acaroğlu E, Ateş B, et al. (2004). Comparison of anterior instrumentation systems and the results of minimum 5 years follow-up in the treatment of tuberculosis spondylitis. Kobe J Med Sci, 50(5-6): 167-180.

Bian Z, Gui Y, Feng F, Shen $H$ and Lao L. (2020). Comparison of anterior, posterior, and anterior combined with posterior surgical treatment of thoracic and lumbar spinal tuberculosis: a systematic review. J. Int Med Res, 48(2): 300060519830827.

Boachie-Adjei O, Papadopoulos EC, Pellisé F, Cunningham ME, PerezGrueso FS, Gupta M, et al. (2013). Late treatment of tuberculosis-associated kyphosis: literature review and experience from a SRS-GOP site. Eur Spine J, 22 Suppl 4(Suppl 4): 641-646.

Broner FA, Garland DE and Zigler JE. (1996). Spinal infections in the immunocompromised host. Orthop Clin North Am, 27(1): 37-46.

Chen WJ, Wu CC, Jung CH, Chen LH, Niu CC and Lai PL. (2002). Combined anterior and posterior surgeries in the treatment of spinal tuberculous spondylitis. Clin Orthop Relat Res, (398): 50-59.

Chen YC, Chang MC, Wang ST, Yu WK, Liu CL, Chen TH. (2003). Onestage posterior surgery for treatment of advanced spinal tuberculosis. J Chin Med Assoc, 66(7): 411-417.

Dobson J. (1972). Percivall Pott. Annals of the Royal College of Surgeons of England, 50(1): 54-65.

Fisahn C, Alonso F, Hasan GA, Tubbs RS, Dettori JR, Schildhauer TA, et al. (2017). Trends in Spinal Surgery for Pott's Disease (2000-2016): An Overview and Bibliometric Study. Global Spine J, 7(8): 821-828.

Frankel HL, Hancock DO, Hyslop G, Melzak J, Michaelis LS, Ungar GH, et al. (1969). The value of postural reduction in the initial management of closed injuries of the spine with paraplegia and tetraplegia. I. Paraplegia, 7(3): 179-192.

Garg B, Kandwal P, Nagaraja UB, Goswami A, Jayaswal A. (2012). Anterior versus posterior procedure for surgical treatment of thoracolumbar tuberculosis: A retrospective analysis. Indian J Orthop, 46(2): 165-170.

Hodgson AR, Skinsnes OK, Leong CY. (1967). The pathogenesis of Pott's paraplegia. J. Bone Joint Surg Am, 49(6): 1147-1156.

Hodgson AR, Stock FE, Fang HS, Ong GB. (1960). Anterior spinal fusion. The operative approach and pathological findings in 412 patients with Pott's disease of the spine. Br J Surg, 48: 172-178.

Jain AK; Jain S. (2012). Instrumented stabilization in spinal tuberculosis. Int Orthop, 36(2): 285-292. 
K. JA. (2010). Tuberculosis of the spine. 92-B(7): 905-913.

Keynan O, Fisher CG, Vaccaro A, Fehlings MG, Oner FC, Dietz J, et al. (2006). Radiographic measurement parameters in thoracolumbar fractures: a systematic review and consensus statement of the spine trauma study group. Spine (Phila Pa 1976), 31(5): E156-165.

Kuklo TR, Polly DW, Owens BD, Zeidman SM, Chang AS, Klemme WR. (2001). Measurement of thoracic and lumbar fracture kyphosis: evaluation of intraobserver, interobserver, and technique variability. Spine (Phila Pa 1976), 26(1): 61-65; discussion 66.

Kulchavenya E. (2014). Extrapulmonary tuberculosis: are statistical reports accurate? Therapeutic advances in infectious disease, 2(2): 61-70.

Lee CK, Vessa P, Lee JK. (1995). Chronic disabling low back pain syndrome caused by internal disc derangements. The results of disc excision and posterior lumbar interbody fusion. Spine (Phila Pa 1976), 20(3): 356-361.

Lee SH, Sung JK, Park YM. (2006). Single-stage transpedicular decompression and posterior instrumentation in treatment of thoracic and thoracolumbar spinal tuberculosis: a retrospective case series. J Spinal Disord Tech, 19(8): 595-602.

Luk KD. (1999). Tuberculosis of the spine in the new millennium. European spine journal: official publication of the European Spine Society, the European Spinal Deformity Society, and the European Section of the Cervical Spine Research Society, 8(5): 338-345.

Oga M, Arizono T, Takasita M, Sugioka Y. (1993). Evaluation of the risk of instrumentation as a foreign body in spinal tuberculosis. Clinical and biologic study. Spine (Phila Pa 1976), 18(13): 1890-1894.

Pigrau-Serrallach $C$ and RodríguezPardo D. (2013). Bone and joint tuberculosis. Eur Spine J., 22 Suppl 4(Suppl 4): 556-566.

Rajasekaran S. (2001). The natural history of post-tubercular kyphosis in children. Radiological signs which predict late increase in deformity. $\mathrm{J}$ Bone Joint Surg Br, 83(7): 954-962.

Rajasekaran S. (2007). Buckling collapse of the spine in childhood spinal tuberculosis. Clin Orthop Relat Res, 460: 86-92.

Rajasekaran S, Khandelwal G. (2013). Drug therapy in spinal tuberculosis. Eur Spine J., 22 Suppl 4(Suppl 4): 587-593.

Rajasekaran S, Soundararajan DCR, Shetty AP, Kanna RM. (2018). Spinal Tuberculosis: Current Concepts. Global spine journal, 8(4 Suppl): 96S-108S.

Sahoo MM, Mahapatra SK, Sethi GC, Dash SK. (2012). Posterior-only approach surgery for fixation and decompression of thoracolumbar spinal tuberculosis: a retrospective study. J Spinal Disord Tech, 25(7): E217-223.

Singh S, Dawar H, Das K, Mohapatra B, Prasad S. (2017). Functional and Radiological Outcomes of Anterior Decompression and Posterior Stabilization via Posterior Transpedicular Approach in Thoracic and Thoracolumbar Pott's Disease: A Retrospective Study. Asian Spine J., 11(4): 618-626.

Turgut M. (2001). Spinal tuberculosis (Pott's disease): its clinical presentation, surgical management, and outcome. A survey study on 694 patients. Neurosurg Rev, 24(1): 8-13.

Varatharajah S, Charles YP, Buy X, Walter A, Steib JP. (2014). Update on the surgical management of Pott's disease. Orthop Traumatol Surg Res, 100(2): 229235.

Wang X, Pang X, Wu P, Luo C, Shen X. (2014). One-stage anterior debridement, bone grafting and posterior instrumentation vs. single posterior debridement, bone grafting, and instrumentation for the treatment of thoracic and lumbar spinal tuberculosis. Eur Spine J., 23(4): 830-837.

Wibaux C, Moafo-Tiatsop M, Andrei I, Biver E, Cotten A, Cortet B, et al. (2013). Changes in the incidence and management of spinal tuberculosis in a 
French university hospital rheumatology department from 1966 to 2010. Joint Bone Spine, 80(5): 516-519.

Yin XH, Yan L, Yang M, Zhang K, He BR, Liu ZK, et al. (2018). Posterolateral decompression, bone graft fusion, posterior instrumentation, and local continuous chemotherapy in the surgical treatment of thoracic spinal tuberculosis. Medicine (Baltimore), 97(51): e13822.

Zeng H, Zhang P, Shen X, Luo C, Xu Z, Zhang Y, et al. (2015). One-stage posterior-only approach in surgical treatment of single-segment thoracic spinal tuberculosis with neurological deficits in adults: a retrospective study of 34 cases. BMC Musculoskelet Disord, 16: 186. 